\title{
Development of rat metabolic syndrome models: A review
}

\author{
Shirly Gunawan ${ }^{1,2}$ (D), Ahmad Aulia ${ }^{3}$ (i) and Vivian Soetikno ${ }^{4}$ (D) \\ 1. Department of Pharmacology, Faculty of Medicine, Universitas Tarumanagara, Jakarta, Indonesia; 2. Doctoral \\ Programme in Biomedical Science Faculty of Medicine, Universitas Indonesia, Jakarta, Indonesia; 3. Department \\ of Histology, Faculty of Medicine, Universitas Indonesia, Jakarta, Indonesia; 4. Department of Pharmacology and \\ Therapeutics, Faculty of Medicine, Universitas Indonesia, Jakarta, Indonesia. \\ Corresponding author: Shirly Gunawan, e-mail: shirlyg@fk.untar.ac.id \\ Co-authors: AA: aljuswin04@yahoo.com, VS: vivian.soetikno@ui.ac.id \\ Received: 15-02-2021, Accepted: 27-05-2021, Published online: 07-07-2021
}

doi: www.doi.org/10.14202/vetworld.2021.1774-1783 How to cite this article: Gunawan S, Aulia A, Soetikno V (2021) Development of rat metabolic syndrome models: A review, Veterinary World, 14(7): 1774-1783.

\begin{abstract}
Metabolic syndrome (MetS) has become a global problem. With the increasing prevalence of MetS worldwide, understanding its pathogenesis and treatment modalities are essential. Animal models should allow an appropriate representation of the clinical manifestations of human conditions. Rats are the most commonly used experimental animals for the study. The development of a proper MetS model using rats will contribute to the successful application of research findings to the clinical setting. Various intervention methods are used to induce MetS through diet induction with various compositions, chemicals, or a combination of both. This review will provide a comprehensive overview of several studies on the development of rat MetS models, along with the characteristics of the clinical manifestations resulting from each study.
\end{abstract}

Keywords: high-fat diet, high-fructose diet, high-sucrose diet, metabolic syndrome, rat models.

\section{Introduction}

Metabolic syndrome (MetS), also known as syndrome $\mathrm{X}$, is a collection of metabolic disorders, including hypertension, glucose metabolism disorders, insulin resistance, obesity, and dyslipidemia [1]. Each MetS component is an independent risk factor for cardiovascular disease, and the combination of these risk factors elevates the severity of cardiovascular disease [2]. Furthermore, these components and their combination increase the risk of type 2 diabetes mellitus [3]. The American Heart Association/ National Heart, Lung, and Blood Institute and the National Cholesterol Education Program Adult Treatment Panel III have established that MetS is diagnosed when three or more of the following criteria are present: Waist circumference of more than $102 \mathrm{~cm}$ in men and more than $88 \mathrm{~cm}$ in women, fasting plasma glucose of more than or equal to $100 \mathrm{mg} / \mathrm{dL}$ (5.6 mmol/L), systolic blood pressure of more than or equal to 130 and diastolic blood pressure of more than or equal to $85 \mathrm{mmHg}$, triglyceride plasma levels of more than or equal to $150 \mathrm{mg} / \mathrm{dL}(1.7 \mathrm{mmol} / \mathrm{L})$, and high-density lipoprotein (HDL) cholesterol levels of $<40 \mathrm{mg} / \mathrm{dL}(1.03 \mathrm{mmol} / \mathrm{L})$ in men and $<50 \mathrm{mg} / \mathrm{dL}$ (1.29 $\mathrm{mmol} / \mathrm{L})$ in women [1]. MetS has become a global health problem. Worldwide, the prevalence of MetS reaches 20\%-30\% and increases with age in a sex-specific manner [4].

Copyright: Gunawan, et al. Open Access. This article is distributed under the terms of the Creative Commons Attribution 4.0 International License (http://creativecommons.org/licenses/ by/4.0/), which permits unrestricted use, distribution, and reproduction in any medium, provided you give appropriate credit to the original author(s) and the source, provide a link to the Creative Commons license, and indicate if changes were made. The Creative Commons Public Domain Dedication waiver (http:// creativecommons.org/publicdomain/zero/1.0/) applies to the data made available in this article, unless otherwise stated.
With the increasing prevalence of MetS, understanding its pathogenesis and treatment modalities using animal models are essential. The development of proper models has contributed to the successful application of research findings to the clinical setting. Animal models should allow an appropriate representation of the clinical manifestations of human conditions. Rats (Rattus norvegicus) have been used as animal models for investigating MetS [5-7]. However, no experimental rat model has become the standard reference for MetS models. Studies have used various intervention methods to induce MetS, whether through diet induction with various compositions, chemicals, or a combination of both.

This review provides the readers a comprehensive overview of several studies on developing rat MetS models, along with the characteristics of clinical manifestations resulting from each study. Some factors could influence the study results, including the type of diet, duration of induction, strain, and gender and age of the animals at the beginning of induction.

\section{Rats as Animal Models}

To date, rats, mice, dogs, pigs, and rabbits have been used as animal models [5]. However, not all studies can produce clinical manifestations of MetS as in humans. Rats and mice from the rodent group are the most frequently used models to replicate human disease's phenotype and pathogenesis, especially hypertension, diabetes, and obesity [6]. The rodent group could tolerate well to various types of diets. Wistar and Sprague-Dawley outbred rats can be considered the most common rodents used to develop MetS models since they are susceptible to diet-induced obesity and resistance with individual characteristics [8]. Besides the ease of handling, their larger size than 
mice simplifies measuring some metabolic parameters, such as blood pressure $[5,8]$. Nevertheless, they occasionally present some drawbacks because some strains do not develop all MetS components.

Many variables should be considered when using rats as animal models [9]. In addition to strain, the age of the animals contributes to the successful development of MetS models, as metabolism changes substantially from pre-adult age to adult age. Cheng et al. [10] have shown that rats fed with a high-fat diet $(60 \% \mathrm{kcal})$ produced a complete phenotype of MetS, namely, increased body weight, fat mass, fasting plasma glucose, hypertriglyceridemia, hepatic steatosis, and hypertension. The rats are induced at weaning age (3 weeks). All manifestations occurred more rapidly (4 weeks vs. 6 weeks) than induction performed in adult rats (8 weeks of age). Induction duration is also a strong determinant of the metabolic outcome [9]. Sexual dimorphism due to diet-induced insulin resistance and glucose intolerance is also observed in rats, with males being the most affected [9].

Studies using a MetS model can also be conducted using genetically modified animals, for example, leptin-deficient mice, leptin receptor-deficient mice, Zucker fatty rats, Zucker diabetic fatty rats, DahlS.Z-Leprfa/Leprfa rats, Goto-Kakizaki rats, obese spontaneous hypertensive rat (Koletsky rat), and POUND mice [11].

\section{Development of MetS Model}

\section{Diet-induced models}

Diet plays an essential role in developing the clinical manifestations of MetS. Diet can affect metabolism and body regulation through hormones, glucose metabolic pathways, and lipid metabolism [7]. Numerous studies related to metabolic disorders using animal models have been conducted. They used various types of diet and their specific composition, either in the form of mono-diets, such as high-fructose diet, high-sucrose diet, high-fat diet, or the respective combinations of a high-fructose high-fat diet or high-sucrose high-fat diet.

\section{High-carbohydrate diet models}

Carbohydrate is the primary source of energy for the body, which is more readily metabolized than fat. Individuals eating high-carbohydrate diets but with low physical activity tend to store excess energy and develop overweight and obesity. Carbohydrate intake that exceeds energy requirements will increase blood glucose concentrations (Figure-1) [12] and trigger insulin to be secreted from the pancreas and allow cells to uptake glucose. Long-term excessive carbohydrate consumption can cause obesity, which affects insulin resistance.

Recently, Asia's dietary habits have changed with increased intake of refined carbohydrates, sugars, and saturated fats, while the prevalence of MetS is on the rise, especially in Asia [13]. The intake of refined carbohydrates, such as bread, pasta, and sweeteners in drinks, increases the risk of obesity and type 2 diabetes mellitus. However, a high-carbohydrate high-fiber diet helps to prevent cardiovascular diseases and MetS [6,7,13-15].

The simplest form of carbohydrate molecules contains one sugar molecule called monosaccharides, such as glucose, galactose, and fructose. Two monosaccharides joined together are called disaccharides, such as sucrose, which consist of glucose and fructose [16]. The composition and combination of a high-carbohydrate diet are important factors to be considered in developing MetS models. Basic dietary models applied in experimental conditions are the type of carbohydrates, such as, fructose and sucrose.

\section{High-fructose diet models}

Fructose is commonly known as fruit sugar, which is frequently used as a flavor enhancer in foods. Fructose is an intermediate molecule in glucose metabolism and is rapidly absorbed and metabolized by the liver. Its concentration in peripheral blood is less than that of glucose. Its metabolism differs from glucose in ways that make energy consumption likely to increase $[6,17]$. A small fructose quantity produces a lower glycemic response to substitute sucrose and starch in the diet of patients with diabetes $[7,17,18]$.

Nevertheless, fructose intake is large worldwide, which comes from food and beverage sweeteners. Large influx of fructose into the liver causes the accumulation of triglycerides and cholesterol due to the stimulating effects of lipogenesis (Figure-2) [19], which reduces insulin sensitivity leading to insulin resistance and glucose intolerance [17]. A diet containing $60 \%$ fructose of total calories causes hypertension [20] and increases fasting blood sugar, weight gain, and dyslipidemia [6,21-23]. Several studies have shown that a high-fructose diet can induce MetS symptoms and is an essential factor in the development of fatty liver (Table-1) [20-28]. The study by Di Luccia et al. [24] has shown that 8 weeks of induction of a high-fructose diet could induce the early symptoms of obesity. The administration of this diet significantly increases body energy, fat, and plasma levels of non-esterified fatty acids (NEFA), a marker of insulin resistance.

A high-fructose diet can also be delivered by administering $20-30 \%$ fructose in drinking water [25-28]. Nonetheless, these methods show different results. Studies by Ramirez-Higuera et al. [25] and Kubacka et al. [26] on male Wistar rats for 8 weeks have shown increased fasting blood sugar, increased body weight, hypertension, and dyslipidemia. However, the study by Korkmaz et al. has reported the incidence of increased fasting blood sugar and dyslipidemia in male Wistar rats treated with $20 \%$ fructose in drinking water for 15 weeks [27].

Chaturvedi et al. [28] modified the high-fructose diet by administering a combination of $15 \%$ fructose in drinking water for 8 weeks and a high-fructose diet 


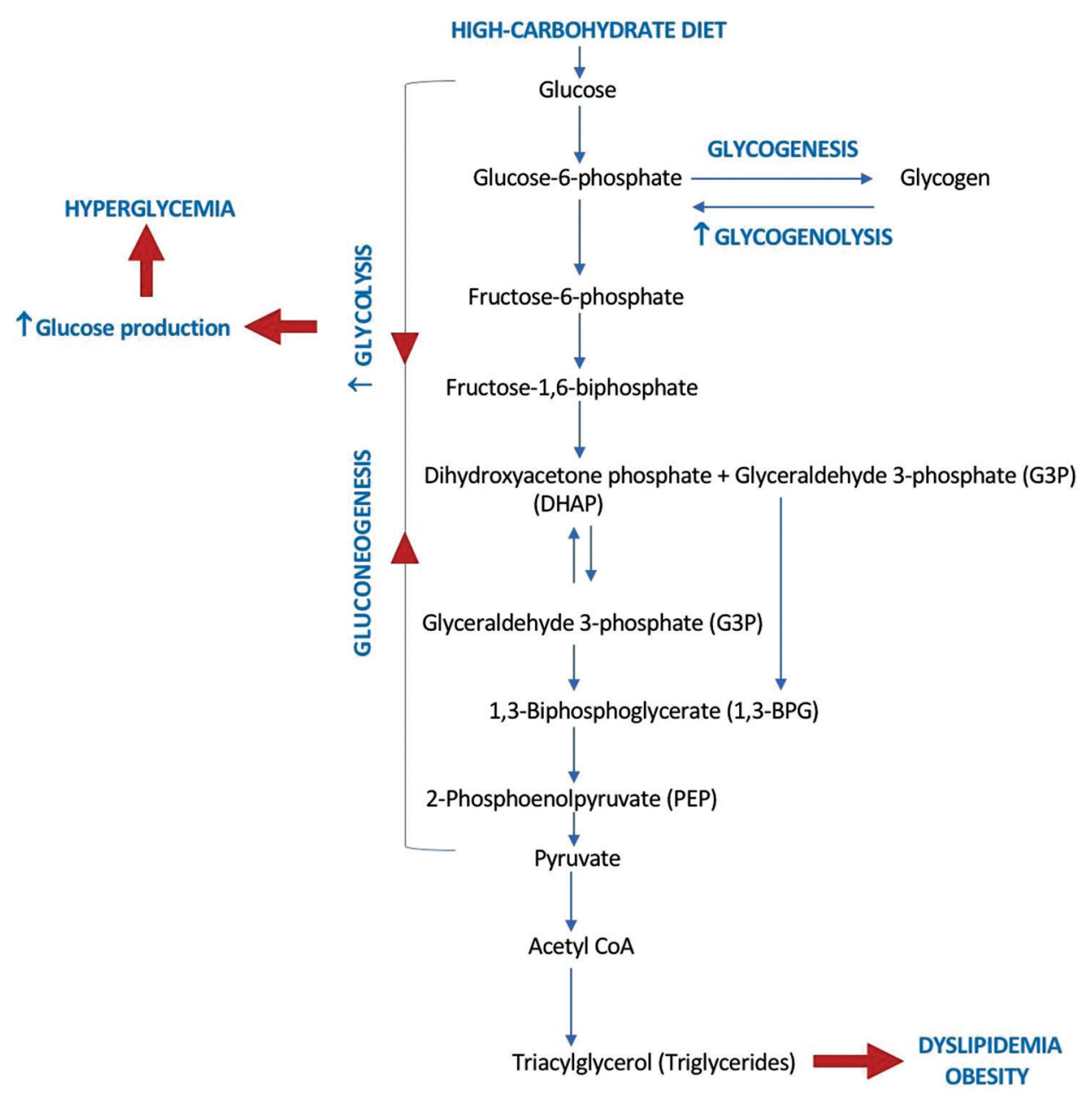

Figure-1: The pathways of glucose metabolism [12].

Table-1: Effects of high-fructose diet on MetS in rat models.

\begin{tabular}{|c|c|c|c|c|c|c|c|c|c|}
\hline \multirow[t]{2}{*}{ Diet variation } & \multirow[t]{2}{*}{ Duration } & \multirow[t]{2}{*}{ Strain } & \multirow{2}{*}{$\begin{array}{l}\text { Age at } \\
\text { induction }\end{array}$} & \multirow{2}{*}{$\begin{array}{l}\text { Weight } \\
\text { (gram) }\end{array}$} & \multicolumn{4}{|c|}{ Components of MetS } & \multirow[t]{2}{*}{ Reference } \\
\hline & & & & & G & $\mathbf{H}$ & $\mathbf{0}$ & D & \\
\hline High-fructose diet (60\%) & 16 weeks & Male SD rats & - & $540-560$ & $\sqrt{ }$ & - & $\sqrt{ }$ & $\sqrt{ }$ & {$[21]$} \\
\hline High-fructose diet (60\%) & 6 weeks & Male Wistar rats & - & $100-110$ & $\sqrt{ }$ & - & $\sqrt{ }$ & $\sqrt{ }$ & {$[22]$} \\
\hline High-fructose diet (60\%) & 6 weeks & Male Wistar rats & - & 234 & $\sqrt{ }$ & - & $\sqrt{ }$ & $\sqrt{ }$ & {$[23]$} \\
\hline High-fructose diet (60\%) & 8 weeks & Male SD rats & 7 weeks & 270 & $\sqrt{ }$ & $\sqrt{ }$ & $\sqrt{ }$ & $\sqrt{ }$ & {$[24]$} \\
\hline $30 \%$ fructose in drinking water & 8 weeks & Male Wistar rats & - & $104-120$ & $\sqrt{ }$ & $\sqrt{ }$ & $\sqrt{ }$ & $\sqrt{ }$ & {$[25]$} \\
\hline $20 \%$ fructose solution & 8 weeks & Male Wistar rats & - & $180-200$ & $\sqrt{ }$ & $\sqrt{ }$ & $\sqrt{ }$ & $\sqrt{ }$ & [26] \\
\hline $\begin{array}{l}20 \% \text { fructose solution in } \\
\text { drinking water }\end{array}$ & 15 weeks & Male Wistar rats & 3 weeks & $280-310$ & $\sqrt{ }$ & - & - & $\sqrt{ }$ & [27] \\
\hline $\begin{array}{l}15 \% \text { fructose in drinking water } \\
\text { continued with high-fructose } \\
\text { diet }(55 \%)\end{array}$ & $\begin{array}{l}8 \text { weeks } \\
2 \text { weeks }\end{array}$ & Male Wistar rats & - & $150-250$ & $\sqrt{ }$ & - & $\sqrt{ }$ & $\sqrt{ }$ & {$[28]$} \\
\hline
\end{tabular}

$\mathrm{G}=$ Hyperglycemia, $\mathrm{H}=$ Hypertension, $\mathrm{O}=$ Obesity, $\mathrm{D}=$ Dyslipidemia $\mathrm{SD}=$ Sprague Dawley

(55\% fructose) for 2 weeks. The results showed an increase in fasting blood sugar, body weight, and the incidence of dyslipidemia.

\section{High-sucrose diet models}

Sucrose is a disaccharide consisting of one fructose molecule and one glucose molecule. Similar to fructose, sucrose serves as a food and beverage sweetener. When it is consumed, sucrose is broken down into glucose and fructose by sucrase. The uptake of glucose in glucose metabolism is negatively regulated by phosphofructokinase, causing a continuous inflow of fructose to the glycolytic pathway. Excess fructose will be converted to fat in the liver, and fructose is a better substrate than glucose for fatty acid synthesis and is the main ingredient that contributes to the development of MetS in animals after consuming sucrose [7]. Acosta-Cota et al. [29] have conducted a study on male Wistar rats, which received drinking water containing sucrose in various concentrations and duration, namely, $30 \%$ sucrose for 12,16 , and 20 weeks and $40 \%$ and $50 \%$ sucrose for 20 weeks. The results showed a significant increase in the rats' body 


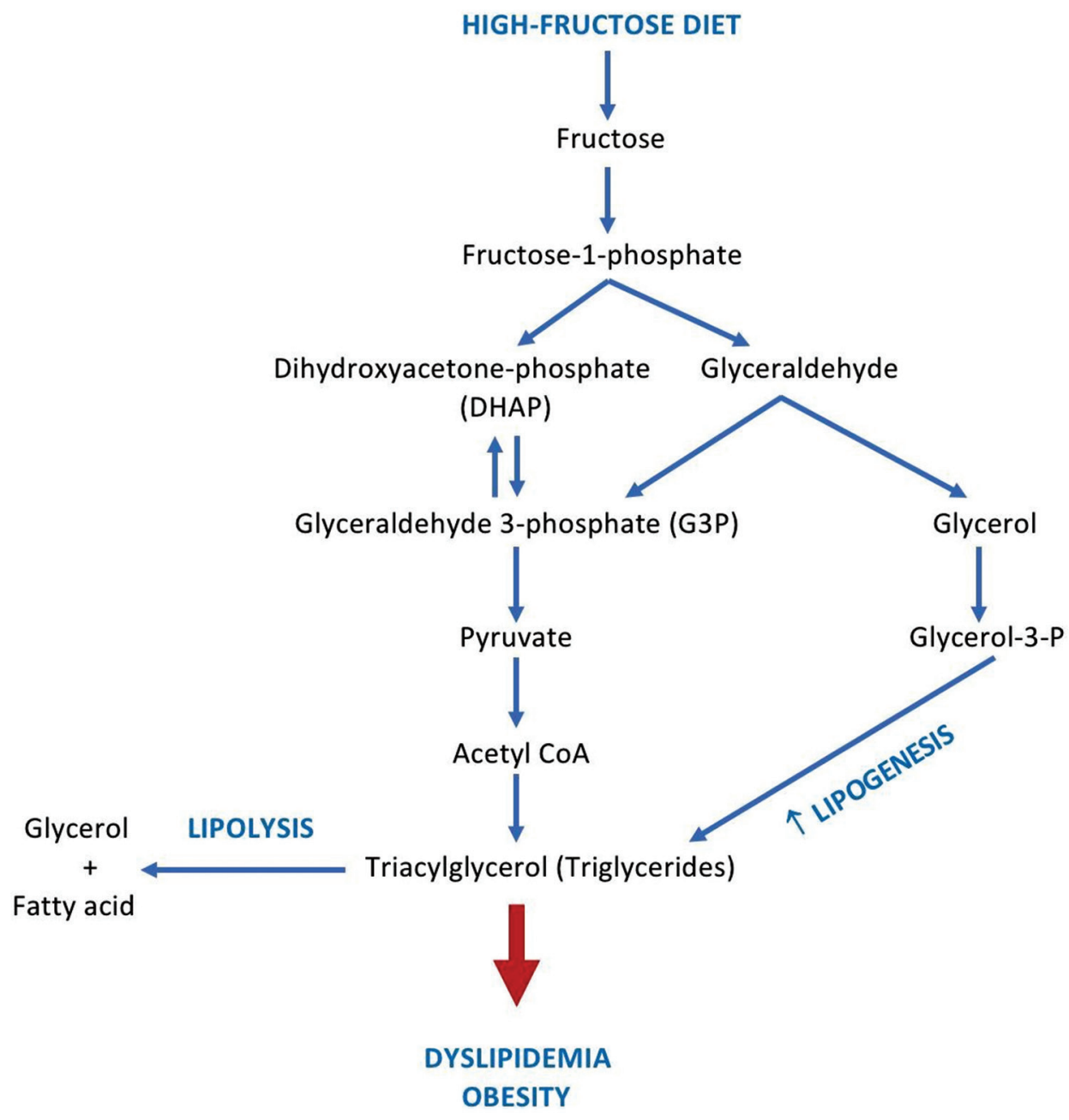

Figure-2: The pathways of fructose metabolism [19].

weight who received $40 \%$ and $50 \%$ sucrose. However, these results were not observed in the group of rats that received $30 \%$ sucrose (Table-2) $[29,30]$. This study showed an increase in blood glucose level, the percentage of intra-abdominal fat, and the incidence of dyslipidemia in all groups. The administration of $30 \%, 40 \%$, and $50 \%$ sucrose reduced the rats' food intake as the taste of sweet drinks and high-carbohydrate levels affected the central nervous system, which produces dopamine and leptin. It decreases appetite and increases the satiety and hedonic responses to get a higher intake of carbohydrates [29]. The higher the sugar concentration in beverages, the higher the hedonic response, resulting in higher sucrose consumption and less food intake. In addition, high-sucrose supplementation causes hyperglycemia, glucose intolerance, and possibly insulin resistance [30].

Villegas-Romero et al. [30] administered 30\% sucrose in drinking water to two groups of male Wistar rats with different durations. The administration of $30 \%$ sucrose in drinking water in the first group started on the $12^{\text {th }}$ day after birth for 28 days (short-term sucrose group), whereas the second group received the solution up to 7 months (long-term sucrose [LTS] group). The results showed an increase in blood pressure in both groups. Meanwhile, for the LTS group, an increase in visceral fat, hyperinsulinemia, hypertriglyceridemia, and Homeostatic Model Assessment of Insulin Resistance was also observed [30]. This study showed that administering a specific diet from an early age is an essential factor in developing hypertension. The administration of sucrose in a relatively short time since post-birth and the weaning period (short window) can create adult rats having hypertension. The possible underlying mechanisms are as follows: (1) Through the effect of insulin, which may increase endothelin-1 concentrations and inhibit endothelial nitric oxide synthase (eNOS); (2) through an increase in free fatty acids, especially oleic acid, whose levels are related to eNOS activity; and (3) through oxidative stress [30]. Fructose appears to be superior to sucrose in inducing MetS, as fructose is present as a free molecule, whereas sucrose consists of $50 \%$ fructose and $50 \%$ glucose [7].

\section{High-fat diet}

Fat is one of the three main macronutrients and is the most calorically dense macronutrient [31]. Different types of high-fat diets have been used to develop MetS models, either from animal-derived fats, such as lard or beef tallow, or from plant oils, 
Table-2: Effects of high-sucrose diet on MetS in rat models.

\begin{tabular}{|c|c|c|c|c|c|c|c|c|c|}
\hline \multirow[t]{2}{*}{ Diet Variation } & \multirow[t]{2}{*}{ Duration } & \multirow[t]{2}{*}{ Strain } & \multirow[t]{2}{*}{ Age at induction } & \multirow[t]{2}{*}{ Weight (gram) } & \multicolumn{4}{|c|}{ Components of MetS } & \multirow[t]{2}{*}{ Reference } \\
\hline & & & & & G & $\mathbf{H}$ & $\mathbf{0}$ & D & \\
\hline \multirow{3}{*}{$\begin{array}{l}30 \% \text { sucrose in } \\
\text { drinking water } 40 \% \\
\text { and } 50 \% \text { sucrose in } \\
\text { drinking water }\end{array}$} & 12,16 , and & Male Wistar & 4 weeks & 80 & $\sqrt{ }$ & - & $\sqrt{ }$ & $\sqrt{ }$ & \multirow[t]{3}{*}{ [29] } \\
\hline & 20 weeks & & & & $\sqrt{ }$ & - & $\sqrt{ }$ & $\sqrt{ }$ & \\
\hline & 20 weeks & & & & $\sqrt{ }$ & - & $\sqrt{ }$ & $\sqrt{ }$ & \\
\hline \multirow{2}{*}{$\begin{array}{l}30 \% \text { sucrose in } \\
\text { drinking water }\end{array}$} & 16 days & Male Wistar & 12 days & 496 & - & $\sqrt{ }$ & - & - & \multirow[t]{2}{*}[30]{} \\
\hline & 7 months & & & 419,67 & - & $\sqrt{ }$ & - & $\sqrt{ }$ & \\
\hline
\end{tabular}

$\mathrm{G}=$ Hyperglycemia, $\mathrm{H}=$ Hypertension, $\mathrm{O}=$ Obesity, $\mathrm{D}=$ Dyslipidemia; $\mathrm{SD}=$ Sprague Dawley

Table-3: Variations of compositions of macronutrients in high-fat diet.

\begin{tabular}{lclc}
\hline \multicolumn{3}{c}{ Compositions of macronutrients } & \multirow{2}{*}{ Reference } \\
\cline { 1 - 2 } Carbohydrate & Protein & \multicolumn{1}{c}{ Fat } \\
\cline { 1 - 2 } $18 \%$ & $12 \%$ & $\begin{array}{l}70 \%(8 \% \text { from soya } \\
\text { oil, 62\% from lard) }\end{array}$ & {$[32]$} \\
$20 \%$ & $20 \%$ & $60 \%$ (lard, casein) & {$[33]$} \\
$28 \%$ & $21 \%$ & $51 \%$ & {$[34]$} \\
$20 \%$ & $20 \%$ & $60 \%$ & {$[35]$} \\
$56 \%$ & $14 \%$ & $30 \%$ (lard) & {$[36]$} \\
\hline
\end{tabular}

such as corn oil, soybean oil, and olive or coconut oil. Diet models containing 30-70\% fat increase body weight; cause hyperglycemia, insulin resistance, and dyslipidemia; and increase free fatty acids in the blood (Table-3) [32-36].

In lipid metabolism, lipid triglycerides are hydrolyzed into glycerol and three fatty acids, which freely diffuse into the bloodstream. Plasma fatty acids are major substrates for hepatic very low-density lipoprotein (VLDL)-triglyceride production. The administration of a high-fat diet will increase VLDL formation, which helps distribute triglycerides (Figure-3) [37]. A high VLDL cholesterol level leads to obesity, dyslipidemia, and a buildup of cholesterol in arteries (Table-4) [8,32-35,38]. The accumulation of triglycerides in the liver can cause insulin resistance [7]. The administration of a high-fat diet also affects NEFA levels, resulting from the breakdown of triglycerides ingested in the diet. In obesity, circulating levels of NEFAs are elevated, and augmented levels are inversely correlated with insulin sensitivity [36].

\section{Combination of High-Fat and High-Carbohydrate Diet Models}

A high-fat, high-carbohydrate diet is a diet model that most closely resembles the current trend toward changing eating habits. Increasing diets that contain large amounts of saturated fat and refined carbohydrates are an essential factor in triggering MetS, obesity, and type 2 diabetes mellitus. Fructose and sucrose, widely used as food or beverage sweeteners, provide less satiety than other sugar types, thus encouraging excessive intake [39].

This combination diet provides several advantages. The increase in triglycerides mainly occurs due to high-fructose diets, whereas obesity occurs due to high-fat diets. This combination diet was associated with an increase in plasma cholesterol levels, a decrease in HDL cholesterol, and a 2-fold increase in liver weight in rats (Table-5) [39-45]. A study has shown the accumulation of lipids in the myocardium, left ventricular hypertrophy, and morphological liver damage. One of the advantages of using a high-fat, high-carbohydrate diet is that damage to heart tissue occurs relatively quickly; thus, examining the morphological, biochemical, and functional properties of cardiovascular pathogenesis in detail is possible [6].

Excessive calorie intake induces fat accumulation leading to deregulation of adipocyte function, resulting in inflammation and free radical production. The inflammatory process plays a key role in insulin resistance, obesity, and glucose intolerance [39]. MorenoFernandez et al. [39] combined a high-fat diet with a high-carbohydrate one, using additional 25\% glucose and $25 \%$ fructose in drinking water, respectively, in two groups. The results showed increased body weight and abdominal circumference in the glucose group, but not in the fructose group. From most studies using a high-fructose diet, the amount that could induce weight gain is more than $30 \%$ fructose $[19,22,24]$.

High Sodium Chloride ( $\mathrm{NaCl}$ ) and High-Fructose Diet

A high $\mathrm{NaCl}$ (salt) diet is used to induce hypertension in rats, but it can also be used to develop MetS models. The administration of high $\mathrm{NaCl}$ content $(8 \%$ $\mathrm{NaCl}$ ) for 2 weeks increased systolic blood pressure, plasma glucose levels, and liver gluconeogenesis [6]. Recent studies have suggested that a high-salt diet activates processes that result in fructose generation in the liver (endogenous fructose production) [46].

The combination of a high $\mathrm{NaCl}$ diet with a high-fructose one $(60 \%)$ increased blood pressure and signs of renal damage [6]. Strong interactions exist between salt and fructose intake. Salt intake may increase thirst, which might encourage the intake of sugary beverages, thereby enhancing fructose intake. High-salt diets are associated with a higher risk of developing diabetes mellitus, regardless of calorie intake. However, the association of salt with fructose may be more complex. Fructose enhances salt absorption in the gut and kidneys and enhances intracellular angiotensin formation. A high-salt diet will activate tonicity-responsive enhancer binding protein 


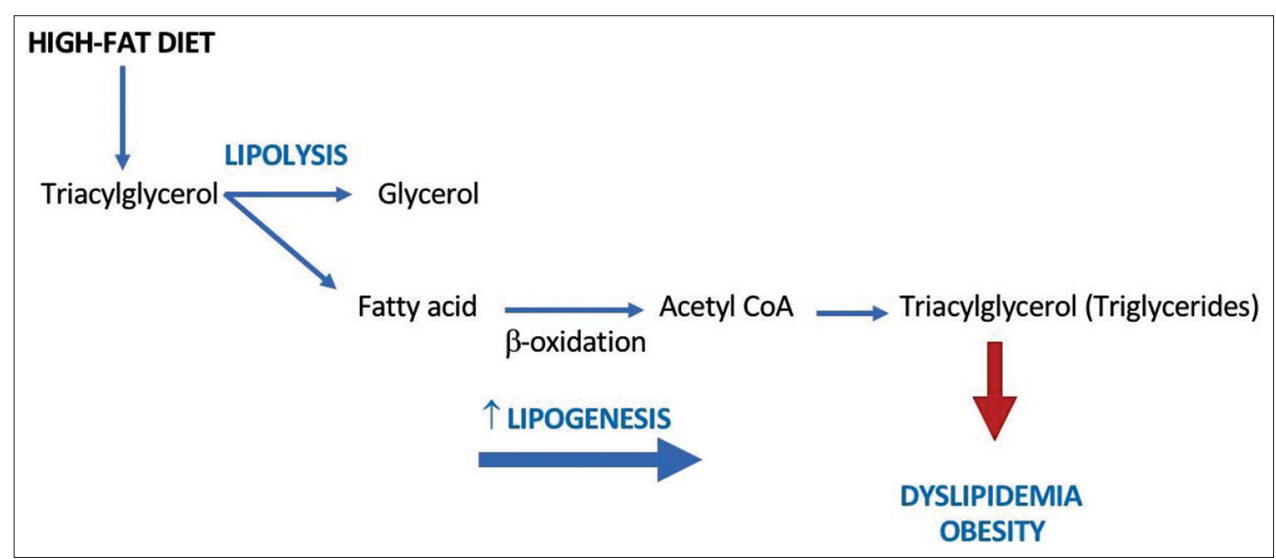

Figure-3: The pathways of lipid metabolism [37].

Table-4: Effects of high-fat diet on MetS in rat models.

\begin{tabular}{|c|c|c|c|c|c|c|c|c|c|}
\hline \multirow[t]{2}{*}{ Diet variation } & \multirow[t]{2}{*}{ Duration } & \multirow[t]{2}{*}{ Strain } & \multirow[t]{2}{*}{ Age at induction } & \multirow[t]{2}{*}{ Weight (gram) } & \multicolumn{4}{|c|}{ Components of MetS } & \multirow[t]{2}{*}{ Reference } \\
\hline & & & & & G & $\mathbf{H}$ & $\mathbf{0}$ & D & \\
\hline High-fat diet (45\%) & 17 weeks & $\begin{array}{l}\text { Male Wistar } \\
\text { Male SD }\end{array}$ & $\begin{array}{l}7 \text { weeks } \\
7 \text { weeks }\end{array}$ & $\begin{array}{l}190 \\
208\end{array}$ & $\begin{array}{l}\sqrt{ } \\
\sqrt{ }\end{array}$ & $\begin{array}{l}- \\
-\end{array}$ & $\begin{array}{l}\sqrt{ } \\
\sqrt{ }\end{array}$ & $\begin{array}{l}- \\
-\end{array}$ & [8] \\
\hline High-fat diet (45\%) & 15 weeks & Male Wistar & 60 days & - & $\sqrt{ }$ & - & $\sqrt{ }$ & $\sqrt{ }$ & [38] \\
\hline High-fat diet (70\%) & 12 weeks & Male SD & 6-7 weeks & $180-220$ & $\sqrt{ }$ & $\sqrt{ }$ & $\sqrt{ }$ & $\sqrt{ }$ & [32] \\
\hline High-fat diet $(60 \%)$ & 10 weeks & Male SD & 6 weeks & 157,5 & $\sqrt{ }$ & - & $\sqrt{ }$ & - & [33] \\
\hline High-fat diet (51\%) & 8 weeks & Male SD & 90 days & $458-494$ & $\sqrt{ }$ & - & $\sqrt{ }$ & $\sqrt{ }$ & [34] \\
\hline High-fat diet $(60 \%)$ & 12 weeks & Male SD & 3 weeks & - & $\sqrt{ }$ & $\sqrt{ }$ & $\sqrt{ }$ & $\sqrt{ }$ & [35] \\
\hline High-fat diet (30\%) & 20 weeks & Male Wistar & - & 409 & $\sqrt{ }$ & $\sqrt{ }$ & $\sqrt{ }$ & $\sqrt{ }$ & {$[8]$} \\
\hline
\end{tabular}

$\mathrm{G}=$ Hyperglycemia, $\mathrm{H}=$ Hypertension, $\mathrm{O}=$ Obesity, $\mathrm{D}=$ Dyslipidemia; $\mathrm{SD}=$ Sprague Dawley

Table-5: Effects of high-fat high-carbohydrate diet on MetS in rat models.

\begin{tabular}{|c|c|c|c|c|c|c|c|c|c|}
\hline \multirow[t]{2}{*}{ Diet variation } & \multirow[t]{2}{*}{ Duration } & \multirow[t]{2}{*}{ Strain } & \multirow{2}{*}{$\begin{array}{l}\text { Age at } \\
\text { induction }\end{array}$} & \multirow[t]{2}{*}{ Weight (gram) } & \multicolumn{4}{|c|}{ Components of MetS } & \multirow[t]{2}{*}{ Reference } \\
\hline & & & & & G & $\mathbf{H}$ & $\mathbf{0}$ & D & \\
\hline $\begin{array}{l}\text { High-fat diet }(22,5 \%)+25 \% \\
\text { glucose in drinking water }\end{array}$ & 20 weeks & Male Wistar & 8 weeks & $280-310$ & $\sqrt{ }$ & - & $\sqrt{ }$ & $\sqrt{ }$ & [39] \\
\hline $\begin{array}{l}\text { High-fat diet }(22,5 \%)+25 \% \\
\text { fructose in drinking water }\end{array}$ & & & & & $\sqrt{ }$ & - & - & $\sqrt{ }$ & \\
\hline $\begin{array}{l}\text { High-fat diet, high- } \\
\text { carbohydrate diet }\end{array}$ & 14 weeks & Male Wistar & 8 weeks & 130 & $\sqrt{ }$ & $\sqrt{ }$ & $\sqrt{ }$ & $\sqrt{ }$ & [40] \\
\hline $\begin{array}{l}\text { High-fat diet, high- } \\
\text { carbohydrate diet+15\% } \\
\text { fructose in drinking water }\end{array}$ & 16 weeks & Male SD & - & $220-250$ & $\sqrt{ }$ & $\sqrt{ }$ & - & $\sqrt{ }$ & [41] \\
\hline $\begin{array}{l}\text { High-fat diet }(66,28 \%)+60 \% \\
\text { fructose in drinking water }\end{array}$ & 4 weeks & Male Wistar & - & - & $\sqrt{ }$ & - & - & $\sqrt{ }$ & {$[42]$} \\
\hline $\begin{array}{l}\text { High-fat diet }(21,4 \%)+25 \% \\
\text { fructose in drinking water] }\end{array}$ & 8 weeks & Male Wistar & - & $185-200$ & $\sqrt{ }$ & - & - & - & {$[43]$} \\
\hline $\begin{array}{l}\text { High-fat diet }+25 \% \text { fructose } \\
\text { in drinking water }\end{array}$ & 16 weeks & Male Wistar & 3 months & $200-250$ & $\sqrt{ }$ & $\sqrt{ }$ & - & $\sqrt{ }$ & [44] \\
\hline $\begin{array}{l}\text { High-fat }(35 \%) \text {, high- } \\
\text { carbohydrate }(45 \%) \text { diet }\end{array}$ & 16 weeks & Male Wistar & 8 weeks & $180-220$ & $\sqrt{ }$ & $\sqrt{ }$ & $\sqrt{ }$ & $\sqrt{ }$ & [45] \\
\hline
\end{tabular}

$\mathrm{G}=$ Fasting hyperglycemia, $\mathrm{H}=$ Hypertension, $\mathrm{O}=$ Obesity, $\mathrm{D}=$ Dyslipidemia SD=Sprague Dawley

(TonEBP), a transcription factor that promotes kidney inflammation and osmolyte production in response to inflammation and osmotic stress. In turn, TonEBP activates the aldose reductase pathway, leading to endogenous fructose generation; this indicates a complex interplay in which salt and fructose synergize together to raise blood pressure (Figure-4) [46].

\section{Chemical-Induced Models}

MetS models can be developed using drugs or chemical substances, such as glucocorticoids, antipsychotics, alloxan, and streptozotocin (STZ) [6,7]. This method is suitable for drug-related MetS studies, but it needs a longer induction duration to meet the criteria for MetS models [46].

\section{Glucocorticoids Induction}

Glucocorticoids are essential steroid hormones secreted from the adrenal gland in response to stress and have been widely prescribed to treat inflammatory disorders and autoimmune diseases. Unfortunately, the therapeutic benefits of glucocorticoids are limited 
due to side effects associated with high-dose and longterm usage. These side effects include osteoporosis, skin atrophy, diabetes, abdominal obesity, glaucoma, cataracts, avascular necrosis and infection, growth retardation, and hypertension [47].

Glucocorticoids contribute to glucose metabolism in the liver, skeletal muscle, adipose tissue, and the pancreas (Figure-5) [48]. Glucocorticoids regulate the expression of major gluconeogenic enzymes in the liver, such as phosphoenolpyruvate carboxykinase, glucose-6-phosphatase, and tyrosine aminotransferase. In skeletal muscles, glucocorticoid excess can inhibit the translocation of glucose transporter type 4 to the plasma membrane in response to insulin, resulting in insulin resistance. Glucocorticoids induce adipocyte differentiation, leading to increased adiposity and insulin resistance [49]. In the pancreas, glucocorticoids induce hyperglycemia by inhibiting glucose-stimulated insulin secretion from $\beta$-cells [50]. Glucocorticoid induction can be administered to animal models by oral feeding, intraperitoneal injections, or surgical implantation of glucocorticoid pellets. These methods will result in almost similar MetS components: Weight gain, abdominal fat accumulation, severe fasting hyperglycemia, insulin resistance, impaired glucose tolerance, hypertension, and dyslipidemia [7].

\section{Antipsychotics Induction}

Antipsychotics form the mainstay of treatment for patients with schizophrenia, bipolar disorder, and other mental disorders. Despite the benefits of these drugs, some animal studies have shown that especially second-generation antipsychotics (SGAs) are associated with weight gain, lipid abnormalities, increased visceral fat, impaired glucose tolerance, and insulin resistance. Thereby, they contribute to the development of MetS and insulin resistance [51]. Among them, olanzapine and clozapine appear to have the highest tendency to disturb glucose metabolism compared with other antipsychotics [52]. The metabolic disturbance mechanisms by SGAs involve both peripheral and central mechanisms. Weight gain is a common side effect of SGAs. The inhibition of hypothalamic 5HT2C and $\mathrm{H} 1$ receptors will result in increased appetite stimulation [53]. Liu et al. [53] have compared olanzapine ( $3 \mathrm{mg} / \mathrm{kg}$, twice a day) with clozapine $(20 \mathrm{mg} / \mathrm{kg}$, twice a day) for 9 weeks to observe the metabolic profile of rats. The study has shown that olanzapine caused weight gain and elevated hepatic lipid levels, which could induce insulin resistance. In addition, clozapine caused weight gain and had an influential direct role in lipid accumulation and insulin secretion deficiency, impairing glucose tolerance.

\section{Alloxan and STZ Induction}

Alloxan (5,5-dihydroxyl pyrimidine-2,4,6-trione) is a toxic glucose analog derived from uric acid oxidation. It can induce diabetes in rodents by producing reactive oxygen species (ROS) that cause the destruction of $\beta$-cells in the pancreas. Its 5 -carbonyl group is reactive to thiol groups, indicating a structure-function relationship in alloxan toxicity.

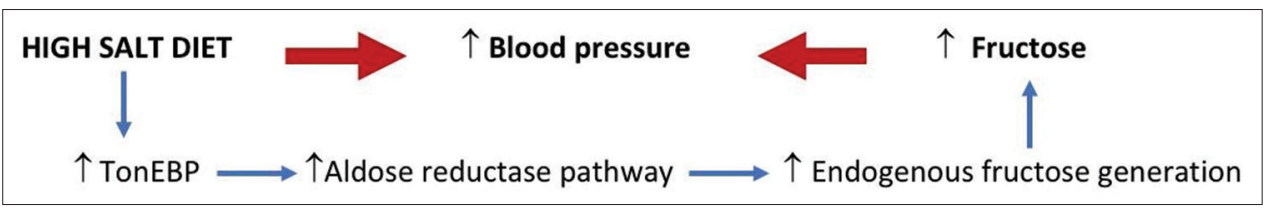

Figure-4: Interaction between high salt diet and endogenous fructose generation [46].

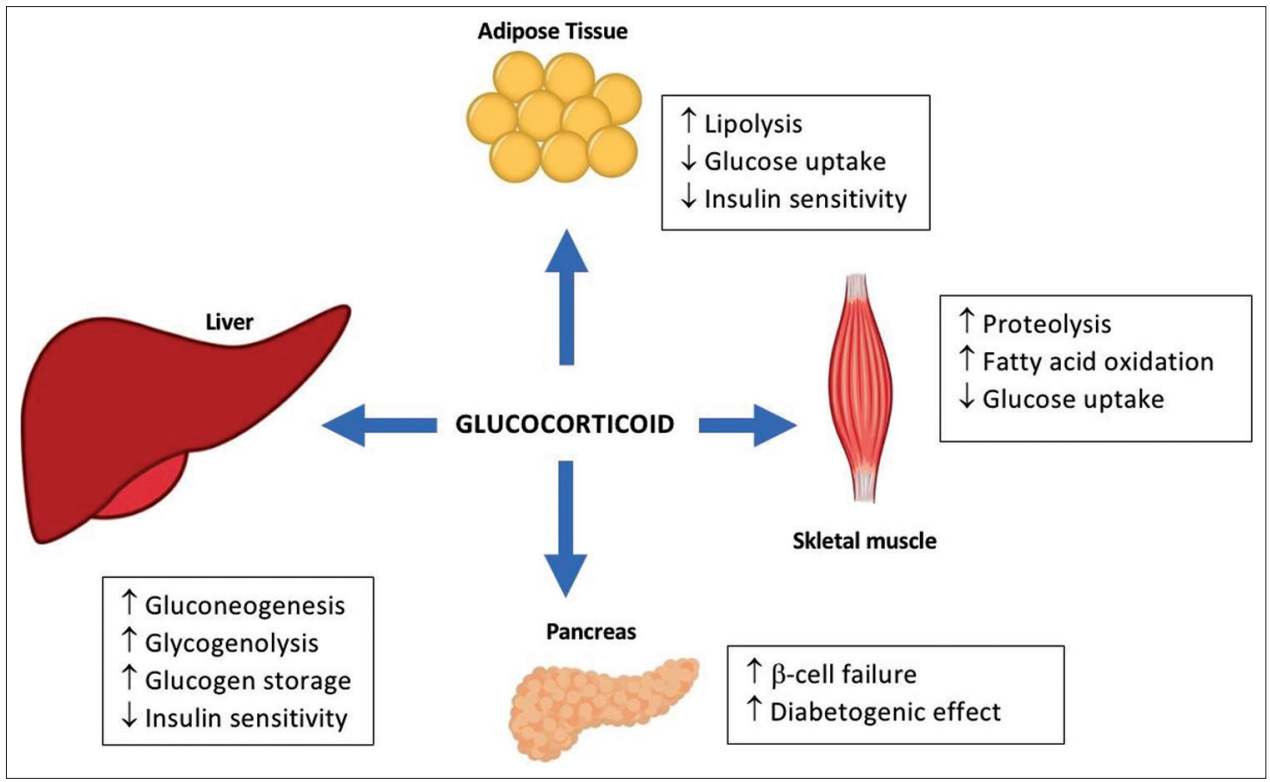

Figure-5: Effects of glucocorticoid on body metabolism [48]. 
Table-6: Effects of high-fat diet/high-fat high-sucrose diet with streptozotocin on MetS in rat models.

\begin{tabular}{|c|c|c|c|c|c|c|c|c|c|}
\hline \multirow[t]{2}{*}{ Diet variation } & \multirow[t]{2}{*}{ Duration } & \multirow{2}{*}{\multicolumn{2}{|c|}{ Strain Age at induction }} & \multirow[t]{2}{*}{ Weight (gram) } & \multicolumn{4}{|c|}{ Components of MetS } & \multirow[t]{2}{*}{ Reference } \\
\hline & & & & & G & $\mathbf{H}$ & $\mathbf{0}$ & D & \\
\hline $\begin{array}{l}\text { High-fat diet }(25 \%)+\mathrm{STZ} \\
(25 \mathrm{mg} / \mathrm{kg})\end{array}$ & 4 weeks & $\begin{array}{l}\text { Male } \\
\text { Wistar }\end{array}$ & 6 weeks & 200 & $\sqrt{ }$ & $\sqrt{ }$ & $\sqrt{ }$ & - & {$[56]$} \\
\hline $\begin{array}{l}\text { High-fat diet }(40 \%) \text {, high- } \\
\text { sucrose diet }(20 \%)+S T Z \\
(30 \mathrm{mg} / \mathrm{kg})\end{array}$ & 8 weeks & $\begin{array}{l}\text { Male } \\
\text { SD }\end{array}$ & 8-12 weeks & $230-340$ & $\sqrt{ }$ & $\sqrt{ }$ & $\sqrt{ }$ & $\sqrt{ }$ & {$[57]$} \\
\hline
\end{tabular}

$\mathrm{G}=$ Hyperglycemia, $\mathrm{H}=$ Hypertension, $\mathrm{O}=$ Obesity, $\mathrm{D}=$ Dyslipidemia; $\mathrm{SD}=$ Sprague Dawley

Its hydrophilic structure is similar to that of glucose, enabling alloxan to be transported into the pancreas involving glucose transporter 2 (GLUT2). In $\beta$-cells of the pancreas, alloxan inhibits glucokinase, the most sensitive thiol enzyme, which has an essential role as a glucose sensor in the pancreas and liver $[54,55]$.

STZ (2-deoxy-2-(3-(methyl-3-nitrosoureido)-D-glucopyranose) is a fungal antitumor antibiotic derived from Streptomyces achromogenes. STZ has properties similar to those of alloxan that contributes to inducing diabetes in animal models, but it has a more selective toxic effect on $\beta$-cells of the pancreas. The most important mechanism of STZ in inducing diabetes is DNA alkylation. In addition, STZ may damage the $\beta$-cell membrane and break DNA strands, leading to cell death. STZ also generates ROS resulting in diabetogenic effects [54].

\section{Combination of High-Fat Diet and STZ Induction}

The administration of a high-fat diet along with STZ induction can develop a type 2 diabetes mellitus model that mimics diabetes mellitus in humans. A high-fat diet will induce insulin resistance in peripheral tissues related to lipotoxicity, while lowdose STZ $(25-30 \mathrm{mg} / \mathrm{kg})$ will induce a mild defect in insulin secretion. The combination of induction can produce metabolic changes that mimic type 2 diabetes mellitus in humans [56,57]. In the study by Jakovljevic et al. [56] male Wistar rats received a high-fat diet and $25 \mathrm{mg} / \mathrm{kg} \mathrm{STZ}$. These combinations can develop MetS components in rats, which had an increase in body weight, hyperglycemia, and hypertension.

Furthermore, in the study by Rohman et al., [57] Sprague-Dawley male rats received a high-fat high-sucrose diet and $30 \mathrm{mg} / \mathrm{kg} \mathrm{STZ}$ to maintain a hyperglycemic state. This experiment produced an animal model representing the complete components of MetS (Table-6) [56,57]. The administration of a high-fat diet induces insulin resistance by activating protein kinase $\mathrm{C}$ induced by a high level of free fatty acid that interfered with the activation of insulin receptor substrate. Dyslipidemia occurs due to an increase in free fatty acids, resulting from the combination diet. Free fatty acids induce inflammation and increase the metabolism of triglycerides and cholesterol. Hypertension occurs due to increased peripheral resistance and the activation of the renin-angiotensin-aldosterone system [57].

\section{Conclusion}

Developing an ideal model of MetS is challenging. Selecting animal models that are appropriate to represent the clinical manifestations of human conditions are essential. Several factors must be considered in developing rat MetS models, including strain, gender, age, induction type, and induction duration. In addition, the models should be reproducible, reliable, and affordable. The development of proper models will contribute to the successful application of research findings to the clinical setting.

\section{Authors' Contributions}

SG: Conception of the specific review, collected literature, and wrote the original manuscript. AA and VS: Contributed to the review, editing, and supported in the supervision. All authors read and approved the final manuscript.

\section{Acknowledgments}

This study was funded by the Ministry of Education, Culture, Research and Technology of the Republic of Indonesia through PDUPT Grant Scheme (No. NKB-142/UN2.RST/HKP.05.00/2021).

\section{Competing Interests}

The authors declare that they have no competing interests.

\section{Publisher's Note}

Veterinary World remains neutral with regard to jurisdictional claims in published institutional affiliation.

\section{References}

1. Alberti, K.G.M., Eckel, R.H., Grundy, S.M., Zimmet, P.Z., Cleeman, J.I., Donato, K.A., Fruchart, J.C., James, W.P.T., Loria, C.M., and Smith, S.C. Jr. (2009) Harmonizing the metabolic syndrome: A joint interim statement of the international diabetes federation task force on epidemiology and prevention; National heart, lung, and blood institute; American heart association; World heart federation; International atherosclerosis society; And international association for the study of obesity, Circulation, 120(16): $1640-1645$

2. Tune, J.D., Goodwill, A.G., Sassoon, D.J. and Mather, K.J. (2017) Cardiovascular consequences on metabolic syndrome. Transl. Res., 183(May): 57-70.

3. Nsiah, K., Shang, V.O., Boateng, K.A. and Mensah, F.O. (2015) Prevalence of metabolic syndrome in Type 2 diabetes mellitus patients. Int. J. Appl. Basic Med. Res., 5(2): 133-138. 
4. Pucci, G., Alcidi, R., Tap, L., Battista, F., Mattace-Raso, F. and Schillaci, G. (2017) Sex-and gender-related prevalence, cardiovascular risk and therapeutic approach in metabolic syndrome: A review of the literature. Pharmacol. Res., 120(Mar): 34-42.

5. Lozano, W.M., Arias-Mutis, O.J., Calvo, C.J., Chorro, F.J. and Zarzoso, M. (2019) Diet-induced rabbit models for the study of metabolic syndrome. Animals, 9(7): 463.

6. Raut, S.K. and Bandawane, D. (2018) A systematic review on animal models of metabolic syndrome. Int. J. Pharm. Res. Health Sci., 6(1): 2089-2098.

7. Wong, S.K., Chin, K.Y., Suhaimi, F.H., Fairus, A. and ImaNirwana, S. (2016) Animal models of metabolic syndrome: A review. Nutr. Metab., 13(65): 1-12.

8. Marques, C., Meireles, M., Norberto, S., Leite, J., Freitas, J., Pestana, D., Faria, A. and Calhau, C. (2016) High-fat diet-induced obesity Rat model: A comparison between Wistar and Sprague-Dawley Rat. Adipocyte, 5(1): 11-21.

9. Preguica, I., Alves, A., Nunes, S., Fernandes, R., Gomes, P., Viana, S.D. and Reis, F. (2020) Diet-induced rodent models of obesity-related metabolic disorders-a guide to a translational perspective. Obes. Rev., 21(12): 1-29.

10. Cheng, H.S., Ton, S.H., Phang, S.C.W. and Tan, J.B.L. (2017) Increased susceptibility of post-weaning rats on highfat diet to metabolic syndrome. J. Adv. Res., 52(8): 743.

11. Kwitek, A.E. (2018) Rat models of metabolic syndrome. Methods Mol. Biol., 2019(2018): 269-285.

12. Bender, D.A. and Mayes, P.A. (2018) Overview of metabolism and the provision of metabolic fuels. In: Harper's Illustrated Biochemistry. $31^{\text {st }}$ ed. McGraw-Hill Education, New York, p336-362.

13. Kwon, Y.J., Lee, H.S. and Lee, J.W. (2017) Association of carbohydrate and fat intake with metabolic syndrome. Clin. Nutr., 37(2): 746-751.

14. Minatel, I.O., Garcia, J.L., Pace, G.P., Lima, G. and Correa, C.R. (2017) The role of carbohydrates in metabolic syndrome. Res Gate., 2017(Jul): 2-26.

15. Sylvetsky, A.C., Edelstein, S.L., Walford, G., Boyko, E.J., Horton, E.S. and Ibebuogu, U.N. (2017) A high-carbohydrate, high-fiber, low fat diet results in weight loss among adults at high risk of Type 2 diabetes. J. Nutr., 147(11): 2060-2066.

16. Holesh, J.E., Aslam, S. and Martin, A. (2020) Physiology, Carbohydrates. StatPearls, Treasure Island, FL. Available from: https://www.ncbi.nlm.nih.gov/books/NBK459280. Retrieved on 28-11-2020.

17. Choo, V.L., Viguiliouk, E., Mejia, S.B., Cozma, A.I., Khan, T.A., Ha, V., Wolever, T.M.S., Leiter, L.A., Vuksan, V., Kendall, C.W.C., de Souza R.J., Jenkins, D.J.A. and Sievenpiper, J.L. (2018) Food sources of fructose-containing sugars and glycaemic control: Systematic review and meta-analysis of controlled intervention studies. $B M J$, 363(Nov): k4644.

18. Basaranoglu, M., Basaranoglu, G. and Buginesi, E. (2015) Carbohydrate intake and nonalcoholic fatty liver disease: Fructose as a weapon of mass destruction. Hepatobil. Surg. Nutr., 4(2): 109-116.

19. Bender, D.A. and Mayes, P.A. (2018) The pentose phosphate pathway and other pathways of hexose metabolism. In: Harper's Illustrated Biochemistry. $31^{\text {st }}$ ed. McGraw-Hill Education, New York, p452-473.

20. Kho, M.C., Lee, Y.J., Park, J.H., Kim, H.Y., Yoon J.J., Ahn Y.M., Tan, R., Park., M.C., Cha, J.D., Choi, K.M., Kang, D.G. and Lee, H.S. (2016) Fermented red ginseng potentiates improvement of metabolic dysfunction in metabolic syndrome rat models. Nutrients, 8(6): 369.

21. Hsieh, C.C., Liao, C.C., Liao, Y.C., Hwang, L.S., and Wu, L.Y. and Hsieh, S.C. (2016) Proteomic changes associated with metabolic syndrome in a fructose-fed rat model. J. Food Drug Anal., 24(4): 754-761.

22. Sil, R. and Chakraborti, S.A. (2016) Oxidative inactivation of liver mitochondria in high fructose diet-induced metabolic syndrome in rats: Effect of glycyrrhizin treatment. Phytother. Res., 30(9): 1503-1512.

23. Ajiboye, T.O., Aliyu, H., Tanimu, M.A., Muhammad, R.M. and Ibitoye, O.B. (2016) Dioscoreophyllum cumminsii (Stapf) Diels leaves halt high-fructose induced metabolic syndrome: Hyperglycemia, insulin resistance, inflammation and oxidative stress. J. Ethnopharmacol., 4(192): 471-479.

24. Di Luccia, B., Crescenzo, R., Mazzoli, A., Cigliano, L., Venditti, P., Walser, J.C., Widmer, A., Baccigalupi, L., Ricca, E. and Iossa, S. (2015) Rescue of fructose-induced metabolic syndrome by antibiotics or faecal transplantation in a rat model of obesity. PLoS One, 10(8): e0134893.

25. Ramirez-Higuera, A., Montes, C.P., Herrera-Meza, S., Mendoza-Lopez, R., Valerio-Alfaro, G. and OliartRoss, R.M. (2019) Preventive action of sterculic oil on metabolic syndrome development on a fructose-induced rat model. J. Med. Food., 23(3): 1-7.

26. Kubacka, M., Kotanska, M., Syafarz, M., Pociecha, K., Waszkielewicz, A.M., Marona, H., Filipek, B. and Mogilski, S. (2019) Beneficial effects of non-quinazoline a1-adrenolytics on hypertension and altered metabolism in fructose-fed rats. A comparison with prazosin. Nutr. Metab. Cardiovasc. Dis., 29(7): 751-760.

27. Korkmaz, O.A., Sadi, G., Kocabas, A., Yildirim, O.G., Sumlu, E., Koca, H.B., Nalbantoglu, B., Pektas, M.B. and Akar, F. (2019) Lactobacillus helveticus and Lactobacillus plantarum modulate renal antioxidant status in a rat model of fructose-induced metabolic syndrome. Arch. Biol. Sci., 71(2): 265-273.

28. Chaturvedi, A., Ravishankar, B., Rao, N. and Mudugaru, R. (2016) Evaluation of metabolic syndrome signs in two different animal models. PTB Rep., 2(2): 41-44.

29. Acosta-Cota, S.J., Aguilar-Medina, E.M., RamosPayán, R., Ruiz-Quiñónez, A.K., Romero-Quintana, J.G., Montes-Avila, J., Rendon-Maldonado, J.G., SanchezLopez, A., Centurion, D. and Osuna-Martinez, U. (2019) Histopathological and biochemical changes in the development of nonalcoholic fatty liver disease induced by high-sucrose diet at different times. Can. J. Physiol. Pharmacol., 97(1): 23-36.

30. Villegas-Romero, M., Castrejón-Téllez, V., Pérez-Torres, I., Rubio-Ruiz, M.E., Carreón-Torres, E., Diaz-Diaz, E., ValleMondagron, L.D. and Guarner-Lans, V. (2018) Short-term exposure to high sucrose levels near weaning has a similar long-lasting effect on hypertension as a long-term exposure in rats. Nutrients, 10(6): 728.

31. Brown, M.A., Storlien, L.H., Huang, X.F., Tapsell, L.C., Else, P.L., Higgins, J.A. and Brown, I.L. (2010) Dietary fat and carbohydrate composition: Metabolic disease. In: Fat Detection: Taste, Texture and Post Ingestive Effects. CRC Press, Boca Raton, FL. Available from: https://www.ncbi. nlm.nih.gov/books/NBK53531. Retrieved on 28-11-2020.

32. Yao, L., Wei, J., Shi, S., Guo, K., Wang, X., Wang, Q., Chen, D. and Li, W. (2017) Modified lingguizhugan decoction incorporated with dietary restriction and exercise ameliorates hyperglycemia, hyperlipidemia and hypertension in a rat model of the metabolic syndrome. BMC Complement Altern. Med., 17(1): 1-12.

33. Crawford, M.S., and Gumpricht, E. and Sweasea, K.L. (2019) A novel organic mineral complex prevented high fat diet-induced hyperglycemia, endotoxemia, liver injury and endothelial dysfunction in young male Sprague-Dawley rats. PLoS One, 14(8): 1-17.

34. Crescenzo, R., Mazzoli, A., Cacelliere, R., Bucci, A., Naclerio, G., Baccigalupi, L., Cutting, S.M., Ricca, E. and Iossa, S. (2017) Beneficial effects of carotenoid-producing cells of Bacillus indicus HU16 in a rat model of diet-induced metabolic syndrome. Benef. Microbes., 8(5): 823-831.

35. Cheng, H.S., Phang, S.C.W., Ton, S.H., Kadir, K.A. and Tan, J.B.L. (2018) Purified ingredient-based high-fat diet is superior to chow-based equivalent in the induction of metabolic syndrome. J. Food Biochem., 43(2): 1-11. 
36. Nascimento, A., Gomes, F., Machado, M.V., Goncalvesde-Albuquerque, C., Bousquet, P. and Tibirica, E. (2019) I1-imidazoline receptor-mediated cardiovascular and metabolic effects in high-fat diet-induced metabolic syndrome in rats. Basic Clin., 217(Mar): 18-25.

37. Botham, K.M. and Mayes, P.A. (2018) Metabolism of acylglycerols and sphingolipids. In: Harper's Illustrated Biochemistry. $31^{\text {st }}$ ed. McGraw-Hill Education, New York, p564-610.

38. Ramalho, L., da Jornada, M.N., Antunes, L.C. and Hidalgo, M.P. (2017) Metabolic disturbances due to a high-fat diet in a non-insulin resistant animal model. Nutr. Diabetes., 7(3): e245.

39. Moreno-Fernandez, S., Garces-Rimon, M., Vera, G., Astier, J., Landrier, J.F. and Miguel, M. (2018) High fat/ high glucose diet induces metabolic syndrome in an experimental rat model. Nutrients, 10(10): 1502.

40. Hao, L., Lu, X., Sun, M., Li, K., Shen, L. and Wu, T. (2015) Protective effects of L-arabinose in high-carbohydrate, high-fat diet-induced metabolic syndrome in rats. Food Nutr. Res., 59(Dec): 28886.

41. Senaphan, K., Kukongviriyapan, U., Sangartit, W., Pakdeechote, P., Pannangpetch, P., Prachaney, P., Greenwald, S.E. and Kukongviriyapan, V. (2015) Ferulic acid alleviates changes in a rat model of metabolic syndrome induced by high-carbohydrate, high-fat diet. Nutrients, 7(64): 6446.

42. Hidayati, L., Widodo, A.D.W. and Hidayat, B. (2020) Animal models with metabolic syndrome markers induced by high fat diet and fructose. Med. Lab. Technol. J., 6(1): 13-20.

43. Belhadj, S., Dal, S., Khaskhoussi, F., Maillard-Pedracini, E., Hentati, O. and Sigrist, S. (2020) Anorexic and metabolic effect of jojoba: Potential treatment against metabolic syndrome and hepatic complications. Nutr. Metab., 30(17): 24.

44. Wong, S.K., Chin, K.Y., Suhaimi, F.H., Ahmad, F. and ImaNirwana, S. (2018) The effects of a modified high-carbohydrate high-fat diet on metabolic syndrome parameters in male rats. Exp. Clin. Endocrinol. Diabetes., 126(4): 205-212.

45. Palachai, N., Wattanathorn, J., Muchimapura, S. and Thukham-Mee, W. (2019) Antimetabolic syndrome effect of phytosome containing the combined extracts of mulberry and ginger in an animal model of metabolic syndrome. Oxid. Med. Cell Longev., 6(Nov): 1-19.

46. Eren, O.C., Ortiz, A., Afsar, B., Covic, A., Kuwabara, M., Lanaspa, M.A., Johnson, R.J. and Kanbay, M. (2019) Multilayered interplay between fructose and salt in development of hypertension. Hypertension, 73(2): 265-272.

47. Ramamoorthy, S. and Cidlowski, J.A. (2016) Corticosteroids-mechanisms of action in health and disease. Rheum. Dis. Clin. North Am., 42(1): 15-31.

48. Bonaventura, A. and Montecucco, F. (2018) Steroidinduced hyperglycemia: An underdiagnosed problem or clinical inertia? A narrative review. Diabetes Res. Clin. Pract., 139(May): 203-220.

49. Akaletou, E., Genser, L. and Rutter, G.A. (2020) Glucocorticoid metabolism in obesity and following weight loss. Front. Endocrinol., 11(Feb): 59.

50. Moraitis, A.G., Block, T., Nguyen, D. and Bellanof, J.A. (2017) The role of glucocorticoid receptors in metabolic syndrome and psychiatric illness. J. Steroid. Biochem. Mol. Bio., 165(Pt A): 114-120.

51. Pillinger, T., Mc Cutcheon, R.A., Vano, L., Mizuno, Y., Arumuham, A. and Hindley, G. (2020) Comparative effects of 18 antipsychotics on metabolic function in patients with schizophrenia, predictors of metabolic dysregulation, and association with psychopathology: A systematic review and network meta-analysis. Lancet Psychiatry, 7(1): 64-77.

52. Rodriguez, A.P., Tajima-Pozo, K., Lewczuk, A. and Montanes-Rada, F. (2015) Atypical antipsychotics and metabolic syndrome. Cardiovasc. Endocrinol., 4(5):132-137.

53. Liu, X., Wu, Z., Lian, J., Hu, C.H., Huang, X.F. and Deng, C. (2017) Time-dependent changes and potential mechanism of glucose-lipid metabolic disorders associated with chronic clozapine or olanzapine treatment in rats. Sci. Rep., 7(1): 2762.

54. Ighodaro, O.M., Adeosun, A.M. and Akinloye, O.A. (2017) Alloxan-induced diabetes, a common model for evaluating the glycemic-control potential of therapeutic compounds and plant extracts in experimental studies. Medicina, 53(6): 365-374.

55. Radenkovic, M., Stojanovic, M. and Prostran, M. (2015) Experimental diabetes induced by alloxan and streptozotocin: The current state of the art. J. Pharmacol. Toxicol. Methods., 78(Mar-Apr): 13-31.

56. Jakovljevic, V., Milic, P., Bradic, J., Jeremic, J., Zivkovic, V., Srejovic, I., Tumic, T.N., Milosavljevic, I., Jeremic, N., Bolevich, S., Borovic, M.L., Mitrovic, M. and Vucic, V. (2019) Standardized Aronia melanocarpa extract as novel supplement against metabolic syndrome: A rat model. Int. J. Mol. Sci., 20(1): 6.

57. Rohman, M.S., Lukitasari, M., Nugroho, D.A., Widodo, N., Nugraheini, N.I.P. and Sardjono, T.W. (2017) Development of an experimental model of metabolic syndrome in Sprague Dawley rat. Res. J. Life Sci., 4(1): 76-86.

\section{$* * * * * * * *$}

